\title{
INIBIÇÃO DO ESCURECIMENTO ENZIMÁTICO DE BANANA MAÇÃ MINIMAMENTE PROCESSADA ${ }^{1}$
}

\author{
Ânderson Adriano Martins MELO ${ }^{2}$, Eduardo Valério de Barros VILAS BOAS ${ }^{2, *}$
}

\section{RESUMO}

Objetivou-se, neste trabalho, avaliar o efeito do ácido ascórbico (AA), do cloreto de cálcio (CC), do cloridrato de L-cisteína (Cis) e EDTA, na prevenção do escurecimento enzimático de banana maçã minimamente processada. Foram utilizadas as combinações: (i) $\mathrm{AA} 1 \%+\mathrm{CC} 1 \%+\mathrm{Cis} 0,5 \%$, (ii) $\mathrm{AA} 1 \%+\mathrm{CC} 1 \%+\mathrm{Cis} 1 \%$, (iii) AA $1 \%+\mathrm{CC} 1 \%+\mathrm{Cis} 1,5 \%$ e (iv) EDTA $1 \%$, constituindo quatro tratamentos de um delineamento inteiramente casualizado. Produtos minimamente processados não tratados quimicamente não foram analisados, considerando-se seu acentuado escurecimento e sua vida de prateleira inferior a $6 \mathrm{~h}$. As bananas foram tratadas com hipoclorito de sódio, fatiadas, imersas nos tratamentos químicos, acondicionadas em embalagens rígidas envoltas com filme PVC $30 \mu \mathrm{m}$ e armazenadas durante cinco dias a $5 \pm 1{ }^{\circ} \mathrm{C}$ e $85+3 \%$ UR. Amostras foram analisadas diariamente, durante os cinco dias de armazenamento. Os tratamentos contendo AA $1 \%+\mathrm{CC} 1 \%+\mathrm{Cis} 1 \%$ e AA $1 \%+\mathrm{CC} 1 \%+$ Cis $1,5 \%$ determinaram os maiores valores de acidez titulável e menores de $\mathrm{pH}$. Observaram-se aumentos no valor a* e redução nos valores $\mathrm{b}^{*} \mathrm{e} \mathrm{L}^{*}$ na banana maçã minimamente processada, independente do tratamento químico, durante o armazenamento. O tratamento $\mathrm{AA} 1 \%+\mathrm{CC} 1 \%+\mathrm{Cis} 1,5 \%$ foi o mais efetivo na prevenção das modificações dos valores $\mathrm{a}^{*}, \mathrm{~b}^{*} \mathrm{e} \mathrm{L*}$, associados à coloração das rodelas. Observou-se aumento na atividade da polifenoloxidase (PPO) e peroxidase (POD) durante o armazenamento das rodelas de banana, independente do tratamento, à exceção da redução observada na atividade da PPO, nos produtos tratados com EDTA. Os tratamentos contendo EDTA e AA $1 \%+$ CC $1 \%+$ Cis $1,5 \%$ foram os mais efetivos na contenção do aumento das atividades da PPO e POD, respectivamente.

Palavras-chave: ácido ascórbico, cisteína, cloreto de cálcio, EDTA, Musa sp.

\section{SUMMARY}

ENZIMATIC BROWNING INHIBITION OF FRESH-CUT APPLE BANANA. The goal of this work was to evaluate the effect of ascorbic acid (AA), calcium chloride (CC), L-cysteine hydrochloride (Cys) and EDTA on prevention of enzymatic browning of fresh-cut apple banana. The following combinations were used: (i) AA $1 \%+\mathrm{CC} 1 \%+$ Cys $0.5 \%$, (ii) AA $1 \%+\mathrm{CC} 1 \%+\mathrm{Cys} 1 \%$ (iii) AA $1 \%+\mathrm{CC} 1 \%+\mathrm{Cys}$ $1.5 \%$ e (iv) EDTA $1 \%$, building up four treatments of a completely randomly design. Fresh-cut products without chemical treatment were not analyzed because they browned quickly and presented less than $6 \mathrm{~h}$ of shelf life. The bananas were treated with sodium hypochlorite, sliced, dipped in chemical treatments, put in packages sealed with $30 \mu \mathrm{m}$ PVC film and stored for five days at $5 \pm 1{ }^{\circ} \mathrm{C}$ and $85 \pm 3 \% \mathrm{RH}$. Samples were evaluated every day, during five days of storage. The treatments contenting AA $1 \%+\mathrm{CC} 1 \%+\mathrm{Cis} 1 \%$ and $\mathrm{AA} 1 \%+\mathrm{CC} 1 \%+\mathrm{Cis} 1.5 \%$ determined the higher values of titratable acidity and lower values of $\mathrm{pH}$. Increasing in a* value and decreasing in $\mathrm{b}^{*}$ and $\mathrm{L}^{*}$ values on fresh-cut apple banana were observed, in spite of chemical treatment, during the storage. AA $1 \%$ $+\mathrm{CC} 1 \%+\mathrm{Cis} 1.5 \%$ treatment was the most effective on prevention of changes in $\mathrm{a}^{*}, \mathrm{~b}^{*}$ and $\mathrm{L}^{*}$ values, associated to color of slices. Increasing in polyphenoloxidase (PPO) and peroxidase (POD) activity was observed during the storage of banana slices, despite the treatment, except a decreasing observed on PPO activity, on products treated with EDTA. Treatments contenting EDTA and AA $1 \%+\mathrm{CC} 1 \%+\mathrm{Cis} 1.5 \%$ were the most effective on contention of increasing of PPO and POD activities, respectively.

Keywords: ascorbic acid, cysteine, calcium chloride, EDTA, Musa sp.

\section{1 - INTRODUÇÃO}

As frutas e hortaliças minimamente processadas ou fresh-cut são produtos que sofreram operações de limpeza, lavagem, seleção, descascamento e corte, até chegarem a um produto $100 \%$ aproveitável, que é embalado, a fim de se oferecer, aos consumidores, frescor, conveniência e qualidade nutricional [5].

A banana constitui-se, normalmente, peça-chave de saladas de frutas, embora apresente o inconveniente do rápido escurecimento, que põe em xeque a vida de prateleira desses produtos. A banana escurece poucos minutos

\footnotetext{
${ }^{1}$ Recebido para publicação em 24/1/2005. Aceito para publicação em 23/1/2006 (001466)

${ }^{2}$ Departamento de Ciência dos Alimentos. Universidade Federal de Lavras (Ufla)

CEP 37200-000 - Lavras (MG)

E-mail:evbvboas@ufla.br

*A quem a correspondência deve ser enviada
}

após seu descascamento e corte [16], sendo tal processo associado à elevação da atividade das enzimas polifenoloxidase e peroxidase [15]. Os fenóis encontrados na polpa da banana são oxidados pelas polifenoloxidases, dando origem a quinonas, que se polimerizam e formam os compostos de coloração escura denominados melaninas $[15,16]$. A polifenoloxidase é capaz de oxidar vários substratos, sendo um deles a dopamina, em um pH ótimo de 6,5, para a polpa da banana [19]. As peroxidases agem desestruturando as membranas celulares, diminuindo sua permeabilidade seletiva; promovem, ainda, reações em cadeia que levam à formação de radicais livres que podem causar danos às organelas e membranas, podendo alterar as características sensoriais do produto [15]. Tratamentos químicos à base de cisteína e ácido ascórbico têm sido apontados como efetivos na prevenção do escurecimento de produtos minimamente processados [9, 10, 15, 16, 17].

A cisteína é um aminoácido que contém um grupo tiol, com ação redutora; seu poder de inibição do escurecimento varia de acordo com a razão de concentração cisteína/fenólico 
[11]. Três diferentes mecanismos de atuação de cisteína são propostos: redução das o-quinonas a o-dihidroxifenóis [6]; inibição direta da atividade da polifenoloxidase [2] e reação com o-quinonas dando origem a compostos incolores cis-quinona [12]. Entretanto a aplicação de cisteína pode levar à indesejável formação de pigmentos amarelos, violetas ou róseos [11].

O ácido ascórbico é reconhecido por sua ação redutora e contribuição nutricional (vitamina C). O ácido ascórbico e seus vários sais neutros são os principais antioxidantes para o uso em frutas e hortaliças e seus sucos, visando prevenir escurecimento e outras reações oxidativas [18]. Ele atua seqüestrando o cobre, grupo prostético da polifenoloxidase, e reduzindo quinonas de volta a fenóis, antes de formarem pigmentos escuros [13]. O ácido etilenodiaminotetracético (EDTA) está entre os agentes quelantes mais comumente utilizados na indústria de alimentos, se ligando a íons metálicos, como o cobre, fundamental para a ativação da polifenoloxidase, retardando o efeito dessa enzima [3]. O cloreto de cálcio tem sido aplicado efetivamente na prevenção do amaciamento de frutas minimamente processadas [17], embora possa contribuir, em conjunto com agentes anti-oxidantes, para a prevenção do escurecimento.

Considerando-se a importância da banana na elaboração de saladas de frutas e sua sensibilidade ao escurecimento, bem como a carência de estudos pertinentes à banana minimamente processada, o presente trabalho objetivou avaliar o efeito de tratamentos químicos contendo $\mathrm{CaCl}_{2}$, ácido ascórbico, cloridrato de L-cisteína e $\mathrm{Na}_{2}$ EDTA, sobre a manutenção da qualidade visual e redução na intensidade do escurecimento enzimático de bananas maçã minimamente processadas, armazenadas a $5^{\circ} \mathrm{C}$, por cinco dias, sob atmosfera modificada.

\section{2 - MATERIAL E MÉTODOS}

Foram utilizadas bananas da cultivar maçã, adquiridas no mercado varejista local. As pencas foram selecionadas segundo homogeneidade de cor (casca totalmente amarela) e ausência de defeitos. Posteriormente, os frutos foram submetidos a um pré-resfriamento em câmara fria a $14^{\circ} \mathrm{C}$ por $15 \mathrm{~h}$. As pencas foram inicialmente lavadas em solução de água e sabão neutro. Logo após, foram sanificadas em água fria $\left(10^{\circ} \mathrm{C}\right)$ contendo solução de hipoclorito de sódio $500 \mathrm{mg} . \mathrm{L}^{-1}$, durante $15 \mathrm{~min}$. Em seguida, os frutos foram destacados das pencas, descascados e fatiados manualmente com auxílio de facas afiadas em rodelas de espessura de aproximadamente $1 \mathrm{~cm}$, em ambiente climatizado a $10^{\circ} \mathrm{C}$. As rodelas foram então imersas, por 3 min, nas soluções contendo os seguintes tratamentos químicos: (i) ácido ascórbico $1 \%+$ cloreto de cálcio $1 \%+$ cloridrato de L-cisteína 0,5\%, (ii) ácido ascórbico $1 \%+$ cloreto de cálcio $1 \%+$ cloridrato de L-cisteína $1 \%$, (iii) ácido ascórbico $1 \%+$ cloreto de cálcio $1 \%+$ cloridrato de L-cisteína 1,5\% (iv) $\mathrm{Na}_{2}$ EDTA $1 \%$.

Após a imersão nas soluções, o excesso de líquido foi drenado em peneiras. Em seguida, cerca de $120 \mathrm{~g} \mathrm{de}$ rodelas de bananas foram acondicionadas em bandejas rígidas de polipropileno ( 15 x 11,5 x 4,5 cm - Galvanotek - Ref. G303), as quais foram recobertas por filme de PVC de $30 \mu \mathrm{m}$, e imediatamente armazenadas em câmara fria, com controle de temperatura $\left(5 \pm 1^{\circ} \mathrm{C}\right)$ e umidade relativa ( $85 \pm 3 \%$ UR). O experimento foi conduzido em delineamento inteiramente casualizado (DIC), em esquema fatorial $4 \times 6$, sendo quatro tratamentos químicos, citados anteriormente e cinco tempos de armazenamento $(0,1,2,3,4$ e 5 dias $)$, com três repetições. A parcela experimental constituiu-se de uma bandeja contendo aproximadamente $120 \mathrm{~g}$ de rodelas. Rodelas de bananas não tratadas quimicamente não foram consideradas visto que, a partir de estudos preliminares, constatouse a inviabilidade de comercialização desses produtos, devido ao escurecimento observado em menos de $6 \mathrm{~h}$ após o descascamento e corte.

A determinação da acidez titulável foi realizada no homogenato filtrado em organza, utilizando titulação com $\mathrm{NaOH}$ $0,1 \mathrm{~N}$, de acordo com técnica preconizada pelo INSTITUTO ADOLFO LUTZ [4], e o resultado expresso em gramas de ácido málico por $100 \mathrm{~g}$ de polpa. $\mathrm{O} \mathrm{pH}$ foi determinado no filtrado com um potenciômetro digital, modelo $\mathrm{DMpH}-2$, segundo técnica da AOAC [1]. Foi utilizado para aferição da coloração dos frutos o colorímetro marca Minolta, modelo CR 300, segundo o sistema preconizado pelo CIE ( $\mathrm{L}^{*}$, $a^{*}$ e b*). A extração das enzimas polifenoloxidase (PPO) e peroxidase (POD) foi realizada de acordo com o método descrito por MATSUMO \& URITANI [7]. O tecido congelado foi homogeneizado em politron, com tampão fosfato 0,05 M, pH 7 e imediatamente filtrado em organza. O homogenato obtido foi centrifugado por $10 \mathrm{~min}$ a $5.000 \mathrm{~g}$ e temperatura de $0^{\circ} \mathrm{C}$. O sobrenadante resultante foi utilizado para a determinação de atividade enzimática. A determinação da enzima PPO ocorreu de acordo com o método descrito por TEISSON [14]. Uma alíquota de $1 \mathrm{~mL}$ de extrato enzimático foi adicionada 3,6 mL de tampão fosfato $0,1 \mathrm{M}, \mathrm{pH} 7 \mathrm{e}$ $0,1 \mathrm{~mL}$ de catecol $10 \mathrm{mM}$. A solução obtida foi incubada durante 30 min a $30^{\circ} \mathrm{C}$, e a reação interrompida pela adição de 1,6 mL de ácido perclórico $2 \mathrm{~N}$. A atividade enzimática (PPO) foi expressa em unidade (atividade enzimática capaz de alterar 0,001 de absorbância a $395 \mathrm{~nm}$ ) por grama de polpa fresca por minuto $\left(\mathrm{U}_{\mathrm{g}} \mathrm{g}^{-1} \cdot \mathrm{min}^{-1}\right)$. A determinação da atividade de POD foi realizada de acordo com o método descrito por MATSUMO \& URITANI [7]. Uma alíquota de $3 \mathrm{~mL}$ de extrato enzimático foi pipetada sobre uma solução contendo $5 \mathrm{~mL}$ de tampão fosfato citrato $0,02 \mathrm{M}, \mathrm{pH} 5,0,5 \mathrm{~mL}$ de peróxido de hidrogênio $30 \%$ e $0,5 \mathrm{~mL}$ de guaiacol. A solução foi incubada a $30^{\circ} \mathrm{C}$ por 5 min, e a reação interrompida pela adição de $1 \mathrm{~mL}$ de bissulfito de sódio $30 \%$. A atividade da enzima (POD) foi expressa em unidade (atividade capaz de alterar 0,001 de absorbância a $470 \mathrm{~nm}$ ) por grama de polpa fresca por minuto $\left(\mathrm{U} \cdot \mathrm{g}^{-1} \cdot \mathrm{min}^{-1}\right)$. Os resultados das avaliações físico-químicas e bioquímicas foram submetidos à análise de variância sendo as médias comparadas pelo teste de Tukey a $1 \%$ de probabilidade. As análises de regressão foram realizadas baseadas na significância do resultado do teste de $\mathrm{F}$ e os modelos eleitos consoantes com o coeficiente de determinação. 


\section{3 - RESULTADOS E DISCUSSÃO}

As variáveis acidez total titulável (ATT) e pH foram influenciadas interativamente pelos fatores tratamentos químicos e tempo de armazenamento (Figuras 1 e 2). Observou-se, a despeito do tratamento químico, um incremento na ATT dos frutos, até o terceiro dia, seguido de queda, até o quinto dia de armazenamento, enquanto um incremento no $\mathrm{pH}$ foi verificado, principalmente, a partir do quarto dia de armazenamento. Os menores valores de ATT e maiores de $\mathrm{pH}$ foram verificados nos frutos submetidos ao EDTA, ao longo do armazenamento, enquanto os tratamentos contendo ácido ascórbico (AA) $1 \%+$ cloreto de cálcio (CC) $1 \%+$ cisteína (Cis) $1 \%$ e AA $1 \%+\mathrm{CC} 1 \%+$ Cis $1,5 \%$ determinaram os maiores valores de ATT e menores de pH. Logo, os tratamentos AA $1 \%+\mathrm{CC}$ $1 \%+$ Cis $1 \%$ e AA $1 \%+$ CC $1 \%+$ Cis $1,5 \%$ foram os mais efetivos na contenção do consumo de ácidos orgânicos, notadamente no final do período de armazenamento. O aumento da acidez, seguido de queda, concorda com os resultados obtidos por PINHEIRO [8], ao estudar o amadurecimento de banana maçã. Os resultados apresentados no presente trabalho também concordam com os de REIS et al. [10], que observaram aumento na acidez de banana prata minimamente processada até o terceiro dia de armazenamento refrigerado, a $8^{\circ} \mathrm{C}$. Entretanto, ao contrário do observado no presente trabalho, REIS et al. [10] não verificaram influência do tratamento químico contendo AA $1 \%+\mathrm{CC} 1 \%+$ Cis $0,5 \%$ e AA $1 \%+$ CC $1 \%+$ Cis $1 \%$ sobre as variáveis $\mathrm{pH}$ e ATT, durante quatro dias de armazenamento de banana Prata minimamente processada. O escurecimento enzimático é dependente do $\mathrm{pH}$ do tecido vegetal, sendo o pH 6,5 ótimo para a ação da polifenoloxidase em bananas [19], acima do observado na polpa da banana maçã.

Os valores $\mathrm{a}^{*}, \mathrm{~b}^{*} \mathrm{e} \mathrm{L}^{*}$ dizem respeito à coloração dos frutos. Os valores $\mathrm{a}^{*} \mathrm{e} \mathrm{L}^{*}$ sofreram influência da interação entre os tratamentos químicos e tempo de armazenamento, enquanto o valor $\mathrm{b}^{*}$ foi afetado por ambos fatores, isola-

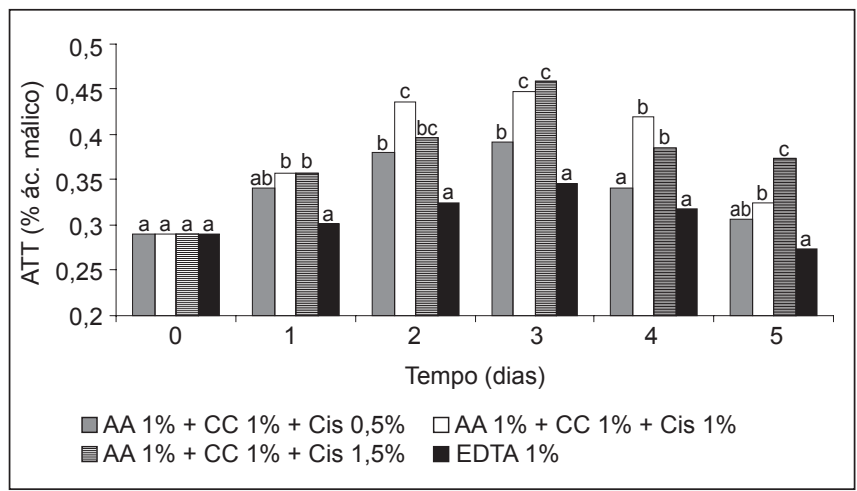

FIGURA 1 - Valores médios de acidez total titulável (ATT) de banana maçã minimamente processada submetida a diferentes tratamentos [ácido ascórbico (AA) 1\%+cloreto de cálcio (CC) 1\%+cloridrato de L-cisteína (Cis) 0,5\%; AA 1\%+CC $1 \%+$ Cis $1 \%$; AA $1 \%+C C$ $1 \%+$ Cis $1,5 \% ; \mathrm{Na}_{2}$ EDTA $1 \%$ ] armazenada a $5 \pm 1^{\circ} \mathrm{C}$ e $85 \pm 3 \%$ UR, por 5 dias. Barras acompanhadas de mesma letra, dentro de cada tempo, não diferem entre si pelo teste de Tukey

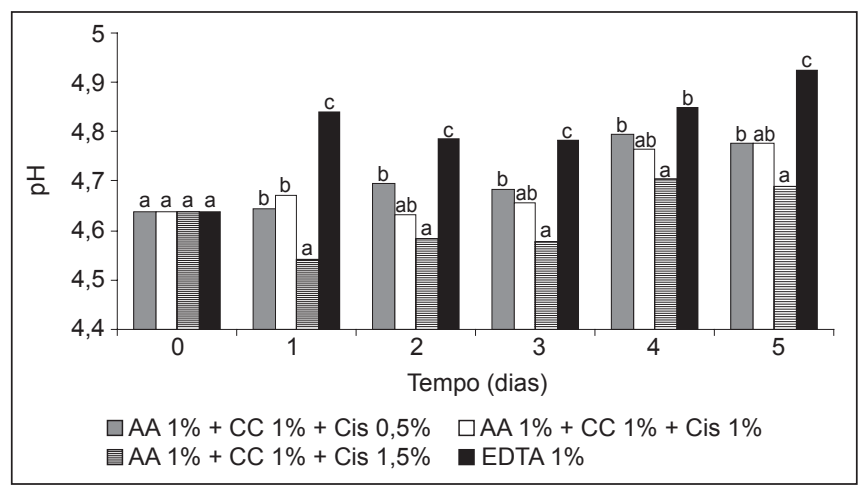

FIGURA 2 - Valores médios de pH de banana maçã minimamente processada submetida a diferentes tratamentos [ácido ascórbico (AA) $1 \%+$ cloreto de cálcio (CC) $1 \%+$ cloridrato de L-cisteína (Cis) $0,5 \%$; AA $1 \%+$ CC $1 \%+$ Cis $1 \%$; AA $1 \%+$ CC $1 \%+$ Cis $1,5 \%$; $\mathrm{Na}_{2}$ EDTA $1 \%$ ] armazenada a $5 \pm 1{ }^{\circ} \mathrm{C}$ e $85 \pm 3 \%$ UR, por cinco dias. Barras acompanhadas de mesma letra, dentro de cada tempo, não diferem entre si pelo teste de Tukey

damente (Figuras 3, 4, 5 e 6). O valor a* varia do verde $\left(-\mathrm{a}^{*}\right)$ ao vermelho $\left(+\mathrm{a}^{*}\right)$. Observaram-se aumentos no valor $\mathrm{a}^{*}$, independente do tratamento químico, durante o armazenamento. O tratamento AA $1 \%+\mathrm{CC} 1 \%+$ Cis $1,5 \%$ determinou os menores valores $\mathrm{a}^{*}$ nos segundo e terceiro dias, enquanto os tratamentos AA $1 \%+\mathrm{CC} 1 \%+\mathrm{Cis} 1, .5 \% \mathrm{e}$ EDTA determinaram os menores valores no quarto e quinto dias (Figura 3). Os maiores valores a* observados nas rodelas tratadas com as combinações de químicos contendo as menores concentrações de cisteína se associam com o roseamento observado nas mesmas, tanto maior quanto menor a concentração de cisteína. Aumentos nos valores a* durante o armazenamento de banana prata minimamente processada também foram observados por REIS [9], sendo tais aumentos mais pronunciados nos produtos submetidos às menores doses de cisteína e associados ao roseamento das rodelas. Esses resultados são condizentes aos apresentados neste trabalho. Segundo RICHARD-FORGET, GOUPY \& NICOLAS [11], a aplicação de cisteína em vegetais fatiados

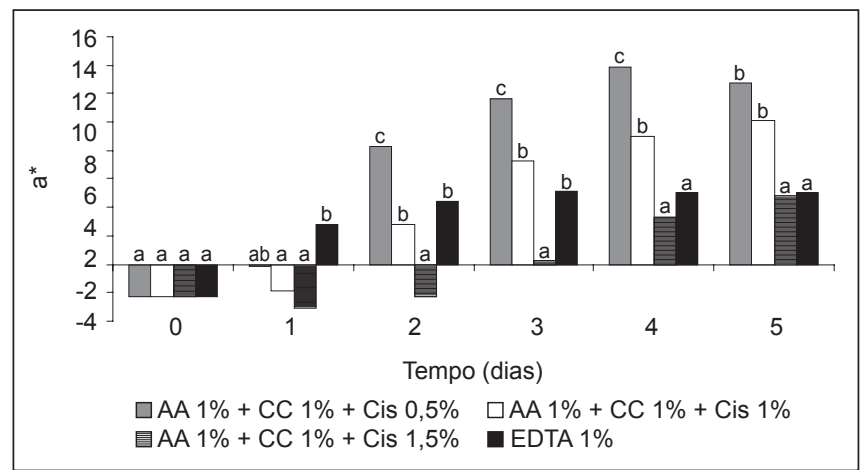

FIGURA 3 - Valores médios da coordenada a* de banana maçã minimamente processada submetida a diferentes tratamentos [ácido ascórbico (AA) $1 \%$ +cloreto de cálcio (CC) 1\%+cloridrato de L-cisteína (Cis) 0,5\%; AA 1\%+CC 1\%+Cis 1\%; AA $1 \%+C C$ $1 \%+$ Cis $1,5 \%$; Na2EDTA $1 \%$ ] armazenada a $5 \pm 1^{\circ} \mathrm{C}$ e $85 \pm 3 \%$ UR, por 5 dias. Barras acompanhadas de mesma letra, dentro de cada tempo, não diferem entre si pelo teste de Tukey 
pode levar à indesejável formação de pigmentos amarelos, violetas ou róseos, como os aqui observados. Os autores sugerem que a pigmentação em fatias de maçãs se deva a formação inicial de cisteína-5-metilcatecol, até toda cisteína ser consumida. Em seguida, o-quinonas em excesso reagem com cisteína-5-metilcatecol, levando à formação de pigmentos violetas. O desenvolvimento da coloração rósea em tecidos vegetais tem sido associado à presença do substrato fenólico epicatequina, antes que metilcatecol [11]. VILAS BOAS [15] afirma que embora a cisteína seja efetiva na prevenção do escurecimento de bananas fatiadas, níveis de cisteína abaixo de $0,5 \%$ são associados com maior incidência de roseamento.

O valor $b^{*}$ varia do azul (-b*) ao amarelo ( $\left.+b^{*}\right)$. Observou-se uma redução do valor $\mathrm{b}^{*}$ com o decorrer do armazenamento (Figura 4). O tratamento AA $1 \%+$ CC $1 \%+$ Cis $1,5 \%$ se diferenciou dos demais por determinar, em média, o maior valor dessa variável (Figura 5), sugerindo maior preservação da sua natural coloração. REIS [9] também observou redução do valor b* em fatias de bananas prata ao longo do armazenamento e a eficácia de maiores doses de cisteína na sua contenção.

O valor $\mathrm{L}^{*}$ demonstra quão claro (maior valor de $\mathrm{L}^{*}$ ) ou quão escuro (menor valor de $\mathrm{L}^{*}$ ) é um produto. Observouse, em geral, redução no valor $\mathrm{L}^{*}$ das rodelas, sugerindo o seu escurecimento ao longo do armazenamento. Os maiores valores $\mathrm{L}^{*}$ foram observados nas rodelas submetidas ao tratamento $\mathrm{AA} 1 \%+\mathrm{CC} 1 \%+\mathrm{Cis} 1,5 \%$, indicando que esse tratamento foi o mais eficiente na prevenção do escurecimento da superfície das rodelas. Os menores valores $\mathrm{L}^{*}$ foram observados nas rodelas tratadas com EDTA, sendo que esses valores foram inferiores, estatisticamente, aos observados nas rodelas tratadas com os demais tratamentos, do primeiro ao quinto dia de armazenamento, a exceção das rodelas tratadas com $\mathrm{AA} 1 \%+\mathrm{CC} 1 \%+\mathrm{Cis} 0,5 \%$, que apresentaram valores $\mathrm{L}^{*}$ semelhantes aos das rodelas sob EDTA, a partir do terceiro dia (Figura 6).

A eficiência de tratamentos químicos contendo AA, CC e Cis, na prevenção do escurecimento, também foi comprovada por REIS [9], ao estudar banana prata minimamente processada armazenada a $8^{\circ} \mathrm{C}$. A autora comprovou, ainda, a maior eficácia do tratamento AA $1 \%+$ CC $1 \%+$ Cis $1 \%$ em comparação ao AA $1 \%+\mathrm{CC} 1 \%+$ Cis $0,5 \%$, no quarto dia de armazenamento.

As atividades das enzimas polifenoloxidase (PPO) e peroxidase (POD) foram afetadas interativamente pelos fatores tratamento químico e tempo de armazenamento (Figuras 7 e 8). Ambas enzimas se associam com os processos de escurecimento nos vegetais. Observou-se aumento na atividade da PPO durante o armazenamento das rodelas tratadas com $\mathrm{AA}+\mathrm{CC}+\mathrm{Cis}$ e redução naquelas tratadas com EDTA. Nenhuma diferença foi notada na atividade da PPO, em função do tratamento químico, até o primeiro dia de armazenamento. No segundo dia, as rodelas tratadas com EDTA apresentaram atividade da $\mathrm{PPO}$ inferior a das rodelas tratadas com AA $1 \%+$ CC $1 \%+$ Cis $0,5 \%$ e AA $1 \%+$ CC $1 \%+$ Cis $1 \%$.

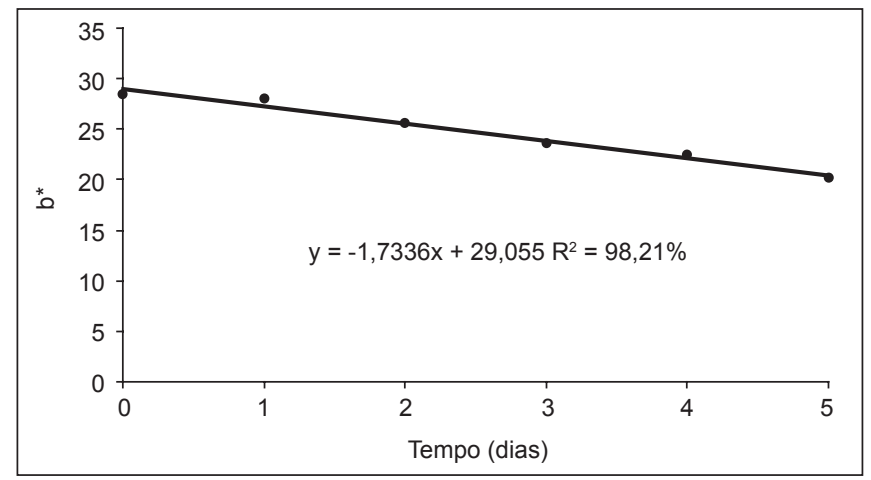

FIGURA 4 - Valores médios, equação de regressão e coeficiente de determinação da coordenada b* banana maçã minimamente processada submetida a diferentes tratamentos [ácido ascórbico (AA) $1 \%+$ cloreto de cálcio (CC) 1\%+cloridrato de L-cisteína (Cis) 0,5\%; AA $1 \%+$ CC $1 \%+$ Cis $1 \%$; AA $1 \%+$ CC $1 \%+$ Cis $1,5 \%$; Na2EDTA $1 \%$ ] armazenada a $5 \pm 1{ }^{\circ} \mathrm{C}$ e $85 \pm 3 \%$ UR, por cinco dias

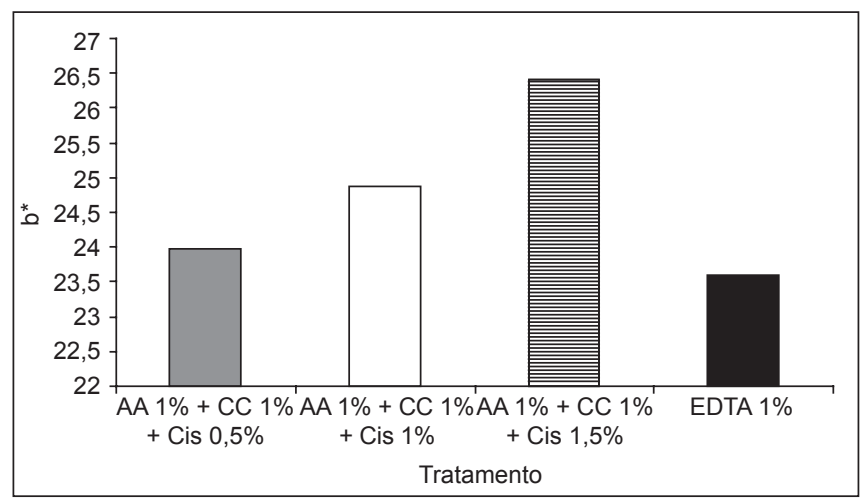

FIGURA 5 - Valores médios da coordenada b* de banana maçã minimamente processada submetida a diferentes tratamentos [ácido ascórbico (AA) 1\%+cloreto de cálcio (CC) 1\%+cloridrato de L-cisteína (Cis) 0,5\%; AA 1\%+CC 1\%+Cis 1\%; AA 1\%+CC $1 \%+$ Cis $1,5 \%$; Na2EDTA $1 \%$ ] armazenada a $5 \pm 1^{\circ} \mathrm{C}$ e $85 \pm 3 \%$ UR, por cinco dias. Barras acompanhadas de mesma letra não diferem entre si pelo teste de Tukey

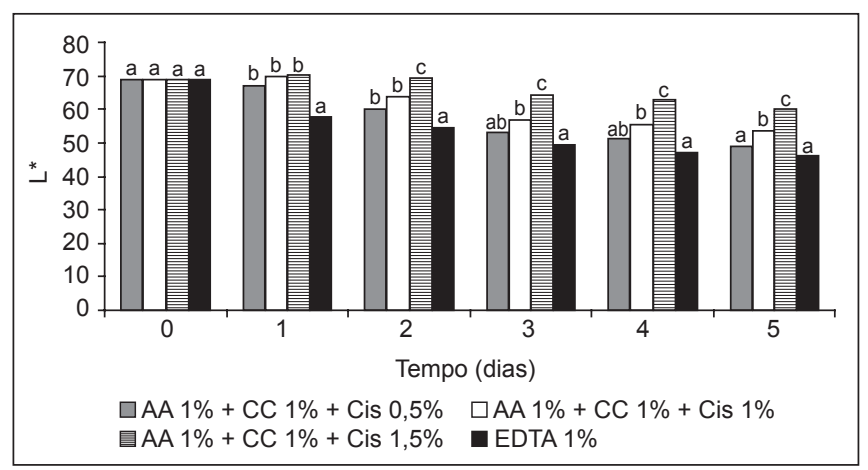

FIGURA 6 - Valores médios da coordenada L* de banana maçã minimamente processada submetida a diferentes tratamentos [ácido ascórbico (AA) 1\%+cloreto de cálcio (CC) 1\%+cloridrato de L-cisteína (Cis) 0,5\%; AA 1\%+CC 1\%+Cis 1\%; AA $1 \%+C C$ $1 \%+$ Cis $1,5 \%$; Na2EDTA $1 \%$ ] armazenada a $5 \pm 1^{\circ} \mathrm{C}$ e $85 \pm 3 \%$ UR, por cinco dias. Barras acompanhadas de mesma letra, dentro de cada tempo, não diferem entre si pelo teste de Tukey 
Do terceiro ao quinto dias as rodelas tratadas com EDTA apresentaram atividade da PPO inferior à das rodelas submetidas aos demais tratamentos, que se comportaram de maneira semelhante. Os tratamentos químicos contendo diferentes concentrações de cisteína $(0,5,1$ e 1,5\%) não influenciaram, diferentemente, a atividade da PPO, à exceção do segundo dia de armazenamento, quando a atividade da PPO das fatias sob $0,5 \%$ de cisteína foi superior à das fatias sob 1 e 1,5\% (Figura 7). Tais resultados são coerentes com os observados por REIS [9], que não notou efeito diferencial da concentração de cisteína (0,5 e 1\%) no tratamento químico contendo AA $1 \%+$ CC $1 \%+$ Cis sobre a atividade de PPO em bananas minimamente processadas, embora o tratamento químico tenha sido efetivo na contenção do natural aumento da PPO. O controle da atividade da PPO pelo EDTA é plausível, visto que este agente quelante se liga ao cobre, fundamental para a ativação da polifenoloxidase [3].

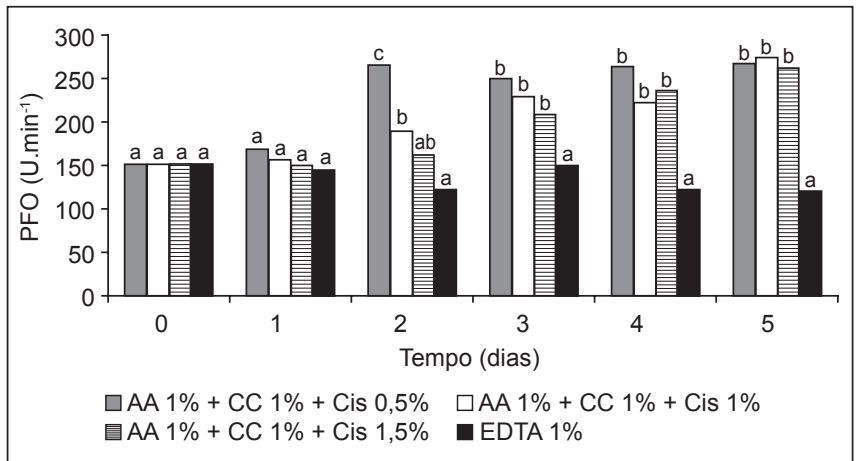

FIGURA 7 - Valores médios da atividade da polifenoloxidase (PPO) de banana maçã minimamente processada submetida a diferentes tratamentos [ácido ascórbico (AA) 1\%+cloreto de cálcio (CC) 1\%+cloridrato de L-cisteína (Cis) 0,5\%; AA $1 \%+$ CC $1 \%+$ Cis $1 \%$; AA $1 \%+$ CC $1 \%+$ Cis $1,5 \%$; Na2EDTA $1 \%$ ] armazenada a $5 \pm 1^{\circ} \mathrm{C}$ e $85 \pm 3 \%$ UR, por cinco dias. Barras acompanhadas de mesma letra, dentro de cada tempo, não diferem entre si pelo teste de Tukey

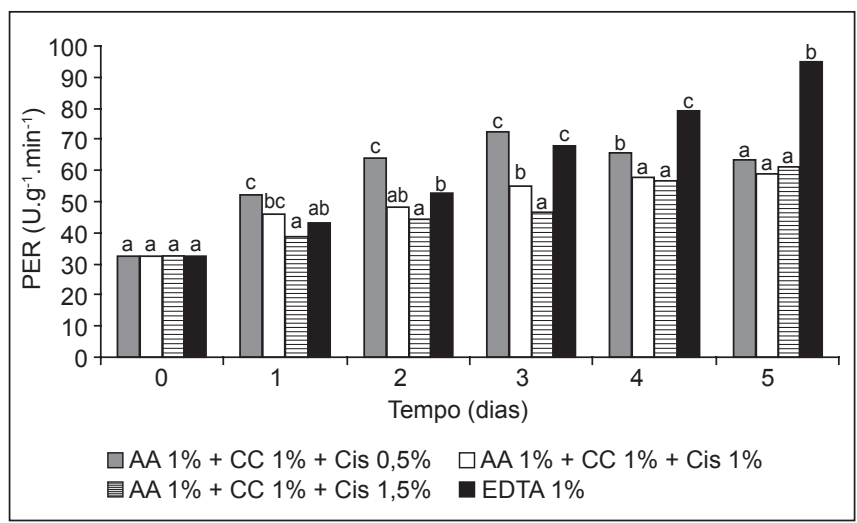

FIGURA 8 - Valores médios da atividade da Peroxidase (POD) de banana maçã minimamente processada submetida a diferentes tratamentos [ácido ascórbico (AA) 1\%+cloreto de cálcio (CC) 1\%+cloridrato de L-cisteína (Cis) 0,5\%; AA 1\%+CC $1 \%+$ Cis $1 \%$; AA $1 \%+C C$ $1 \%+$ Cis $1,5 \%$; Na2EDTA $1 \%$ ] armazenada a $5 \pm 1^{\circ} \mathrm{C}$ e $85 \pm 3 \%$ UR, por cinco dias. Barras acompanhadas de mesma letra, dentro de cada tempo, não diferem entre si pelo teste de Tukey
Observou-se, em geral, incremento na atividade da POD nas rodelas de banana, a despeito do tratamento químico. Os três tratamentos contendo cisteína foram hábeis em conter a atividade da POD, em comparação ao EDTA, a partir do quarto dia de armazenamento, sendo que o tratamento AA $1 \%+\mathrm{CC} 1 \%+$ Cis $1,5 \%$ foi mais efetivo que o EDTA, já a partir do segundo dia.

O tratamento AA $1 \%+\mathrm{CC} 1 \%+$ Cis $1,5 \%$ foi mais efetivo que o AA $1 \%+\mathrm{CC} 1 \%+$ Cis $0,5 \%$ na contenção da atividade da POD, do primeiro ao quarto dia de armazenamento e mais efetivo que o AA $1 \%+\mathrm{CC} 1 \%+\mathrm{Cis}$ $1 \%$, apenas no primeiro e terceiro dias (Figura 8). Os menores valores da coordenada $\mathrm{L}^{*}$ ditados pelo tratamento AA $1 \%+$ CC $1 \%+$ Cis $1,5 \%$ se associaram com as menores atividades de POD observadas nas rodelas sob esse tratamento, embora nenhuma relação tenha sido observada quanto à atividade da PPO. REIS [9] não observou efeito diferencial da concentração de cisteína $(0,5$ e $1 \%)$ em tratamentos químicos contendo AA $1 \%+$ CC $1 \%+$ Cis sobre a atividade de POD, embora o tratamento químico tenha sido efetivo na contenção do seu natural aumento, ao longo do armazenamento de bananas 'Prata' minimamente processadas.

\section{4 - CONCLUSÕES}

- Os tratamentos contendo ascórbico $1 \%+$ cloreto de cálcio $1 \%+$ cisteína $1 \%$ e ascórbico $1 \%+$ cloreto de cálcio $1 \%+$ cisteína $1,5 \%$ determinaram os maiores valores de acidez titulável e menores de $\mathrm{pH}$ nas rodelas de banana maçã.

- O tratamento ácido ascórbico $1 \%+$ cloreto de cálcio $1 \%+$ cisteína $1,5 \%$ foi o mais efetivo na prevenção das modificações dos valores a*, b* e L*, associados à coloração de banana maçã minimamente processada.

- Os tratamentos contendo EDTA e ácido ascórbico $1 \%+$ cloreto de cálcio $1 \%+$ cisteína $1,5 \%$ foram os mais efetivos na contenção do aumento das atividades da polifenoloxidase e peroxidase, respectivamente, em banana maçã minimamente processada.

\section{5 - REFERÊNCIAS BIBLIOGRÁFICAS}

[1] ASSOCIATION OF OFFICIAL ANALYTICAL CHEMISTRY. Official methods of analysis of the Association of Official Analytical Chemistry, $12^{\text {th }}$ ed., Washington, 1.015 p., 1992.

[2] DUDLEY, E.D.; HOTCHKISS, J.H. Cysteine as an inhibitor of polyphenol oxidase. Journal of Food Biochemistry, v. 13, n. 1, p. 65-75, 1989.

[3] DZIEZAK, J.D. Antioxidants. Food Technology, p. 94$102,1986$.

[4] INSTITUTO ADOLFO LUTZ. Normas analíticas, métodos químicos e físicos para análise de alimentos. $3^{\mathrm{a}}$ ed. São Paulo, Instituto Adolfo Lutz, 1985. v. 1, 533 p.

[5] IFPA. 2002. INTERNATIONAL FRESH-CUT PRODUCE ASSOCIATION. Disponível em: < http://www.fresh-cuts. org > . Acesso em: 25 fev. 2003. 
[6] KAHN, V. Effect of proteins, protein hydrolyzates and amino acids on o-dihydroxyphenolase activity of polyphenoloxidase of mushroom, avocado and banana. Journal of Food Science, v. 50, p.111-115, 1985.

[7] MATSUMO, H.; URITANI, I. Physiological behavior of peroxidase enzymes in sweet potato root tissue injured by cutting or black root. Plant Cell and Physiology, v. 13, n. 6, p. 1.091-1.101, 1972.

[8] PINHEIRO, A.C.M. Qualidade pós-colheita de banana maçã submetida ao 1-MCP. 2004.60 p. Dissertação (mestrado em Ciência dos Alimentos), Departamento de Ciência dos Alimentos. Universidade Federal de Lavras (Ufla).

[9] REIS, C.M.F. Manutenção da qualidade de banana prata minimamente processada. 2002. 92 p. Dissertação (mestrado em Ciência dos Alimentos), Departamento de Ciência dos Alimentos. Universidade Federal de Lavras (Ufla).

[10] REIS, C.M.F.; VILAS BOAS, E.V. de B.; BOARI, C.A.; PÍCCOLI, R.H. Qualidade e vida de prateleira de banana prata minimamente processada. Ciência e Agrotecnologia, v. 28, n. 3, p. 702-708, 2004.

[11] RICHARD-FORGET, F.C.; GOUPY, P.M.; NICOLAS, J.J. Cysteine as an inhibitor of enzymatic browning. 2. kinetic studies. Journal of Agricultural and Food Chemistry, v. 40, n. 11, p. 2.108-2.113, 1992.

[12] RICHARD-FORGET, F.C.; GOUPY, P.M.; NICOLAS, J.J.; LACOMBE, J-M; PAIVA, A.A. Cysteine as an inhibitor of enzymatic browning. 1. isolation and characterization of addition compounds formed during oxidation of phenolics by apple polyphenol oxidase. Journal of Agricultural and Food Chemistry, v. 39 n. 5, p. 841-847, 1991.

[13] SAPERS, G.M.; MILLER, R.L. Browning inhibition in fresh-cut pears. Journal of Food Science, v. 63, n. 2, p. 342-346, 1998.
[14] TEISSON, C. Lê brunissement interne de I'ananás. I-Historique. II-Material et méthodos. Fruits, v. 34, n. 4, p. 245-281, 1979.

[15] VILAS BOAS, E.V. de B. Frutas minimamente processadas: banana. III Encontro Sobre Processamento Mínimo de Frutas e Hortaliças: palestras, resumos e oficinas. Viçosa, UFV, p. 111-121. 2004.

[16] VILAS BOAS, E.V. de B. Tecnologia de processamento mínimo de banana, mamão e kiwi. Seminário Internacional de Pós-colheita e Processamento Mínimo de Frutas e Hortaliças. Brasília, Embrapa Hortaliças, p. 1-7. Disponível em cd-rom. 2002.

[17] VILAS BOAS, E.V.de B.; KADER, A.A. Effect of 1-MCP on fresh-cut fruits. Perishables Handling Quarterly, Davis, n. 108, p. 25, november, 2001.

[18] WILEY, R.C. Minimally processed refrigerated fruits and vegetables, London, CHAPMAN e HALL, 357 p., 1994.

[19] YANG, C-P; FUJITA, S.; ASHRAFUZZMAN, M.D.; NAKAMURA, N.; HAYASHI, N. Purification and characterization of polyphenol oxidase from banana (Musa sapientum L.) pulp. Journal of Agricultural and Food Chemistry, v. 48, n. 7, p. 2.732-2.735, 2000.

\section{6 - AGRADECIMENTOS}

Ao $\mathrm{CNPq}$, pelo apoio financeiro para execução do projeto, através das bolsas de produtividade e iniciação científica ao Prof. Dr. Eduardo Valério de Barros Vilas Boas e Eng. Agrônomo Ânderson Adriano Martins Melo, respectivamente. 